\title{
Penanganan Endogenitas Modal Sosial Pada Pemodelan Kemiskinan Rumah Tangga di Indonesia Dengan Metode Two Probit Least Square (2PLS)
}

\author{
Eko Yulian \\ Pusdiklat Badan Pusat Statistik, Jl. Jagakarsa no. 70, Jagakarsa, Jakarta Selatan, Indonesia
}

Korespondensi; Email: okeyulian@gmail.com

\begin{abstract}
Abstrak
Kemiskinan merupakan salah satu permasalahan mendasar yang telah menjadi perhatian utama berbagai negara di dunia termasuk Indonesia. Agar pengentasan kemiskinan berjalan efektif tentunya perlu diketahui dan diukur kuat pengaruh faktor-faktor yang mempengaruhi kemiskinan. Faktor-faktor tersebut diantaranya adalah modal SDM dan modal sosial. Untuk mengukur kontribusi faktor-faktor tersebut digunakan analisis regresi. Variabel bebas pada penelitian ini bersifat kategorik biner ( $1=$ miskin, $0=$ tidak) sehingga analisis regresi yang bisa digunakan adalah analisis regresi logistik dan probit. Penelitian ini menggunakan regresi probit untuk mengetahui pengaruh modal sosial dan modal SDM terhadap kemiskinan. Pada analisis regresi probit, asumsi yang harus dipenuhi adalah tidak adanya korelasi antara variabel bebas dan error pada model, apabila hal tersebut tidak terpenuhi maka akan muncul permasalahan yang disebut dengan endogenitas yang mengakibatkan hasil taksiran parameter yang dihasilkan bias. Pada penelitian ini diperoleh informasi bahwa variabel modal sosial merupakan variabel endogen sehingga digunakan metode Two Probit Least Square (2PLS) untuk mengatasi permasalahan endogenitas yang terjadi. Berdasarkan hasil regresi probit dengan menggunakan metode 2PLS diperoleh tiga variabel bebas yang berpengaruh negatif terhadap peluang rumah tangga menjadi miskin, variabel-variabel tersebut adalah modal sosial, lama sekolah dan umur. Sedangkan variabel ukuran rumah tangga berpengaruh positif terhadap peluang rumah tangga menjadi miskin di Indonesia.
\end{abstract}

Kata Kunci: 2PLS; Endogenitas; Modal sosial; Probit

\begin{abstract}
Poverty is one of the fundamental problems. It has been a major concern of governments in various countries around the world, including Indonesia. In order for poverty alleviation to be effective, it is necessary to know and measured strongly the influence of factors affecting poverty. These factors include human capital and social capital. To measure the contribution of these factors is used regression analysis. The independent variables in this study are binary categorical $(1=$ poor, $0=$ no) so that regression analysis that can be used is logistic and probit regression analysis. This research uses probit regression to know the influence of social capital and human capital to poverty. In the probit regression analysis, the assumption that must be met is the absence of correlation between the independent variable and error in the model, if it is not fulfilled then the problem will arise called endogeneity which can lead to bias parameter. In this study obtained information that social capital variable is an endogenous variable, so Two Probit Least Square (2PLS) method used to overcome the problem of endogeneity that happened. Based on the results of probit regression using 2PLS method obtained three independent variables that negatively affect the probability of households to be poor, these variables are social capital, school, and age. While the variable size of households positively affects the probability of households being poor in Indonesia.
\end{abstract}

Keywords: 2PLS; Endogeneity; Probit; Social capital

\section{Pendahuluan}

Berdasarkan data BPS (2017), jumlah penduduk miskin di Indonesia pada tahun 2017 adalah sebanyak 27,77 juta orang atau $10,64 \%$ dari total populasi penduduk. Menurut data yang diperoleh dari Asian Development Bank (ADB, 2017), angka kemiskinan di Indonesia berada diperingkat ke-5 se-Asia 
tenggara di bawah Singapura (0,5\%), Malaysia (0,6\%), Vietnam (7\%), dan Thailand $(10,5 \%)$. Pemerintah Indonesia telah melakukan upaya-upaya untuk mempercepat pengentasan kemiskinan. Hal ini terbukti dari tren angka kemiskinan yang cenderung turun dari tahun ke tahun.

Upaya penanggulangan kemiskinan akan lebih efektif jika diketahui faktor-faktor dan seberapa kuat pengaruh faktor-faktor tersebut dapat mempengaruhi kemiskinan. Analisis faktor-faktor yang menyebabkan kemiskinan atau determinan kemiskinan pernah dilakukan oleh Ikhsan (Ikhsan, 1999). Ikhsan, membagi faktor-faktor determinan kemiskinan menjadi empat kelompok, yaitu modal sumber daya manusia (human capitah), modal fisik produktif (physical productive capitah), status pekerjaan, dan karakteristik desa. Modal SDM dalam suatu rumah tangga merupakan faktor yang akan mempangaruhi kemampuan suatu rumah tangga untuk memperoleh pekerjaan dan pendapatan.

Selain modal SDM, terdapat modal lain yang berpotensi dalam masalah pengentasan kemiskinan yaitu modal sosial. Fukuyama, 1995, berhasil meyakinkan bahwa modal sosial memiliki kekuatan untuk mempengaruhi prinsip-prinsip yang melandasi kemajuan ekonomi dan kesejahteraan sosial suatu negara. Negara-negara yang dikategorikan sebagai high trust societies, menurut Fukuyama, cenderung memiliki keberhasilan ekonomi yang mengagumkan. Sebaliknya, low trust societies cenderung memiliki kemajuan dan perilaku ekonomi yang lebih lamban dan inferior. Konsep modal sosial telah berkembang selama dua dekade terakhir. Colemann (Coleman, 1988) mengonseptualisasikan modal sosial secara sistematis. Putnam, 1993, menganalisis partisipasi masyarakat (modal sosial) dikaitkan dengan kemajuan pembangunan di Italia. Kesimpulanya modal sosial yang tinggi mendorong pembangunan di Italia. Woolcock \& Narayan, 2000, menyatakan bahwa modal sosial merupakan norma dan jaringan kerja yang memungkinkan orang melakukan sesuatu secara bersama-sama. Ada hubungan yang erat antara modal sosial dan modal manusia. Modal sosial adalah hasil dari hubungan antar individu yang memfasilitasi suatu tindakan bersama. Meskipun konsep modal sosial dipahami secara berbeda, telah terjadi konvergensi menuju definisi yaitu berfokus pada jaringan, norma-norma, dan nilai-nilai bersama yang memfasilitasi kerjasama diantara kelompok-kelompok (Healy \& Hampshire, 2002).

Agar pengentasan kemiskinan berjalan efektif tentunya perlu diketahui dan diukur kuat pengaruh faktor-faktor yang mempengaruhi kemiskinan. Faktor-faktor tersebut diantaranya adalah modal SDM dan modal sosial. Pada penelitian ini akan dilihat bagaimana pengaruh modal sosial dan modal SDM terhadap terjadinya kemiskinan di Indonesia. Untuk mengukur kontribusi faktor-faktor tersebut digunakan analisis regresi. Variabel bebas pada penelitian ini bersifat kategorik biner $(1=$ miskin, $0=$ tidak) sehingga analisis regresi yang bisa digunakan adalah analisis regresi logistik dan probit. Perbedaan regresi logistik dan probit terletak pada link function yang digunakan. Regresi logistik menggunakan distribusi kumulatif dari distribusi logistik sebagai link function sedangkan regresi probit menggunakan distribusi normal standar sebagai link function. Pada penelitian ini akan digunakan regresi probit untuk mengetahui pengaruh modal sosial dan modal SDM terhadap kemiskinan. Pada analisis regresi, asumsi yang harus dipenuhi adalah tidak adanya korelasi antara variabel bebas dan error pada model, apabila hal tersebut tidak terpenuhi maka akan muncul permasalahan yang disebut dengan endogenitas yang mengakibatkan hasil taksiran parameter yang dihasilkan bias. Pada kenyataanya variabel modal sosial merupakan variabel endogen di dalam model kemiskinan, seperti yang diungkapkan oleh Adepoju dan Oni, 2012. Seperti halnya pada Analisis regresi, ketika terdapat variabel bebas yang bersifat endogen maka hasil taksiran koefisien regresi probit akan menjadi bias. Oleh karena itu penelitian ini difokuskan terhadap bagaimana mengatasi permasalahan endogenitas (modal sosial terhadap kemiskinan) pada regresi probit.

\section{Landasan Teori}

\section{Endogenitas}

Misalkan dimiliki persamaan regresi sebagai berikut

$$
Y_{i}=\beta_{0}+\beta_{1} X_{i}+\varepsilon_{i}
$$

Asumsi yang perlu dipertahankan agar kita dapat memperoleh estimator tidak bias adalah tidak adanya korelasi antara variabel bebas $\left(X_{i}\right)$ dengan kekeliruan $\left(\varepsilon_{i}\right)$, atau $\operatorname{Cov}\left(X_{i}, \varepsilon_{i}\right)=0$. Namun 
demikian dalam praktek empiris asumsi ini banyak tidak terpenuhi. Terdapat tiga penyebab utama mengapa pelanggaran asumsi ini terjadi, yaitu:

1. Omitted Variable, yang terjadi jika kita tidak memasukkan suatu variabel ke dalam model (dan seharusnya ada).

2. Simultaneity, yang terjadi jika variabel tak bebas pada satu persamaan dapat menjadi variabel bebas pada persamaan lain

3. Measurement error, hal ini terjadi disebabkan oleh adanya ketidakakuratan pengukuran pada variabel bebas. Measurement error pada variabel bebas akan menimbulkan masalah endogenitas, sedangkan measurement error pada variabel tidak bebas tidak akan menimbulkan masalah endogenitas.

\section{Instrumen Variabel (IV)}

Instrumen Variabel (IV) pertama kali diperkenalkan oleh Philip Wright, seorang matematikawan dari Harvard University pada tahun 1928. Ide dasar dari IV adalah mengisolasi dampak endogenitas dari variabel endogen dengan cara mencari suatu variabel baru yang berkorelasi dengan variabel endogen tetapi tidak berkorelasi dengan error model. Misalkan kita memiliki model seperti pada persamaan (1) dan diketahui bahwa $\operatorname{Cov}(X, \varepsilon) \neq 0$. Untuk mendapatkan estimator yang tidak bias, kita memerlukan informasi tambahan yang bisa diperoleh dari suatu variabel baru. Misalkan kita memiliki variabel baru yaitu $Z$. $Z$ dikatakan suatu instrumen variabel jika:

a. Tidak berkorelasi dengan error, $\operatorname{Cov}(Z, \varepsilon)=0$ dan

b. Berkorelasi dengan variabel endogen, $\operatorname{Cov}(Z, X) \neq 0$

\section{Regresi Probit}

Regresi Probit adalah salah satu model regresi yang dapat digunakan untuk mengetahui pengaruh variabel independen terhadap variabel dependen yang bersifat biner (Hill \& Griffiths, 2011). Regresi Probit dikenalkan pertama kali oleh Chester Bliss (1934), seorang biologist yang berasal dari Ohio, Amerika Serikat. Sebelum membahas model probit terlebih dahulu akan dibahas tentang variabel laten $y$. Variabel laten $(y *)$ adalah suatu variabel yang tidak bisa diobservasi atau dilihat, dimana nilai dari variabel laten tersebut berkisar antara $(-\infty,+\infty)$. Adapun model dari variabel laten bisa dituliskan sebagai berikut:

$$
y_{i}^{*}=\beta_{0}+\beta_{1} X_{i 1}+\cdots+\beta_{p} X_{i p}+u_{i}
$$

$y_{i}$ adalah variabel yang teramati, dalam hal ini $y_{i}$ bernilai 1 dan 0 . Variabel laten $y_{i}^{*}$ dapat diinterpretasikan sebagai utility difference antara memilih $y_{i}=1$ atau 0 .

Nilai $y_{i}=1$ jika variabel laten bernilai positif dan 0 selainnya.

$$
y_{i}=\left\{\begin{array}{l}
1 \text { jika } y_{i}^{*}>0 \\
0 \text { jika } y_{i}^{*} \leq 0
\end{array}\right.
$$

Peluang bahwa $y_{i}=1$ adalah

$$
\begin{aligned}
P\left(y_{i}=1 \mid x_{i}\right)=P\left(y_{i}^{*}>0 \mid x_{i}\right) & =P\left(x^{\prime}{ }_{i} \beta+u_{i}>0 \mid x_{i}\right)=P\left(u_{i}>-x^{\prime}{ }_{i} \beta \mid x_{i}\right) \\
& =1-\Phi\left(-x^{\prime}{ }_{i} \beta\right)=\Phi\left(x^{\prime}{ }_{i} \beta\right)
\end{aligned}
$$

Atau bisa ditulis

$$
P\left(Y_{i}=1 \mid x_{i}\right)=\Phi\left(\beta_{0}+\beta_{1} X_{i 1}+\cdots+\beta_{p} X_{i p}\right)
$$

Dimana $\Phi()$ adalah fungsi kumulatif suatu distribusi. Persamaan regresi di atas disebut regresi probit jika fungsi kumulatif distribusi yang digunakan adalah fungsi distribusi kumulatif distribusi normal standar. 


\section{Two Probit Least Square (2PLS)}

Terdapat beberapa metode yang bisa digunakan untuk mengatasi masalah endogenitas pada regresi probit, salah satunya adalah Two Probit Least Square (2PLS) yang dikembangkan oleh Rivers dan Vuong, 1988. Telah disebutkan sebelumnya bahwa pada regresi probit, observasi yang bisa diamati bernilai 1 dan 0 , sedangkan nilai yang dihasilkan oleh satu set variabel independen akan berkisar dari - sampai +. Maka hubungan antara variabel laten dan variabel observasi adalah sebagai berikut:

$$
\begin{gathered}
Y_{i}^{*}=\gamma E_{i}+\beta X_{i}+u_{i} \\
Y_{i}=\left\{\begin{array}{cc}
1, & \text { jika } Y_{i}^{*}>0 \\
0, & \text { jika } Y_{i}^{*} 0
\end{array}\right.
\end{gathered}
$$

Permasalahan yang timbul adalah jika $E_{i}$ adalah variabel endogen pada persamaan (2) maka perlu dilakukan penanganan. Dengan menggunakan metode 2PLS langkah pertama yang dilakukan adalah memodelkan/meregresikan variabel endogen tersebut terhadap variabel instrumen dan variabel eksogen yang ada pada persamaan (2) sebagai berikut:

$$
E_{i}=\delta Z_{i}+\eta X_{i}+v_{i}
$$

dimana

$Y_{i} \quad$ : variabel tak bebas

$E_{i} \quad$ : variabel endogen

$X_{i} \quad$ : variabel eksogen

$Z_{i} \quad$ : variabel instrumen

$u_{i}, v_{i}:$ error term

Kemudian nilai residual yang diperoleh pada (3) dimasukkan ke persamaan (2) sebagai variabel bebas. Prosedur pengerjaan metode 2PLS untuk menangani permasalahan endogenitas yang terjadi pada regresi probit adalah sebagai berikut:

1. Regresikan $E_{i}$ pada $Z_{i}$ dan $X_{i}$ (persamaan 3) untuk mendapatkan $\hat{\delta}$ dan $\hat{\eta}$, sehingga akan diperoleh nilai residual

$$
\hat{v}_{i}=E_{i}-\left(\hat{\delta} Z_{i}+\hat{\eta} X_{i}\right)
$$

2. Masukkan variabel $\hat{v}_{i}$ yang diperoleh pada tahap 1 ke persamaan (2) sebagai variabel bebas. Lakukan analisis probit $Y_{i}$ terhadap variabel-variabel bebas yaitu $E_{i}, X_{i}$, dan $\hat{v}_{i}$.

\section{Sumber Data dan Variabel Penelitian}

Sumber data yang digunakan dalam penelitian ini adalah data modal sosial pada Modul Sosial Budaya Pendidikan (MSBP) Survei Sosial Ekonomi Nasional (Susenas) 2012 (BPS, 2013) dan indikator kesejahteraan masyarakat dari data Susenas 2012. Variabel variabel pada penelitian ini adalah variabel status kemiskinan sebagai variabel tak bebas. Modal sosial, lama sekolah, jenis kelamin, umur, status perkawinan, dan ukuran rumah tangga sebagai variabel bebas. Lama tinggal dan banyaknya organisasi yang diikuti sebagai instrumen variabel. 
Tabel 1. Definisi dan pengukuran variabel dalam model analisis.

\begin{tabular}{|c|c|c|}
\hline Variabel & Definisi & Pengukuran \\
\hline Status kemiskinan rumah tangga $(\mathrm{Y})$ & $\begin{array}{lrr}\text { Rumah } & \text { tangga } & \text { miskin } \\
\text { apabila pengeluaran } & \text { per } \\
\text { kapita di bawah } & \text { Garis } \\
\text { Kemiskinan } & & \end{array}$ & $\begin{array}{l}\text { Bernilai } 1 \text { jika rumah tangga miskin, } 0 \\
\text { jika lainnya }\end{array}$ \\
\hline Skor Modal sosial (M) & $\begin{array}{l}\text { Indeks komposit dari tiga } \\
\text { dimensi modal sosial }\end{array}$ & Bernilai $0-100$ \\
\hline Lama sekolah (X1) & $\begin{array}{l}\text { Pendidikan kepala rumah } \\
\text { tangga yang diukur dari } \\
\text { lama sekolah }\end{array}$ & $\begin{array}{l}\text { Lama sekolah kepala rumah tangga } \\
\text { (tahun) }\end{array}$ \\
\hline Jenis kelamin (X2) & $\begin{array}{l}\text { Jenis kelamin kepala rumah } \\
\text { tangga }\end{array}$ & $\begin{array}{l}\text { Bernilai } 1 \text { jika laki-laki, } 0 \text { jika } \\
\text { perempuan }\end{array}$ \\
\hline Umur (X3) & Umur kepala rumah tangga & Umur kepala rumah tangga (tahun) \\
\hline Status perkawinan (X4) & $\begin{array}{l}\text { Status perkawinan kepala } \\
\text { rumah tangga }\end{array}$ & Bernilai 1 jika menikah, 0 jika lainnya \\
\hline Ukuran rumah tangga (X5) & Ukuran rumah tangga & Banyaknya anggota rumah tangga \\
\hline Lama tinggal (Z1) & $\begin{array}{l}\text { Lama tinggal di lingkungan } \\
\text { sekarang }\end{array}$ & Tahun \\
\hline Banyak organisasi (Z2) & $\begin{array}{l}\text { Banyaknya organisasi yang } \\
\text { diikuti }\end{array}$ & Jumlah organisasi \\
\hline
\end{tabular}

\section{Hasil dan Pembahasan}

\section{Deskriptif Variabel Penelitian}

Terdapat enam variabel prediktor yang diduga berpengaruh terhadap variabel respon status kemiskinan rumah tangga di Indonesia. Keenam variabel prediktor tersebut antara lain adalah modal sosial (M), lama sekolah $(X 1)$, jenis kelamin $(X 2)$, umur $(X 3)$, status perkawinan $(X 4)$, ukuran rumah tangga $(X 5)$.

Tabel 2. Statistik Deskriptif Variabel Dalam Analisis.

\begin{tabular}{lrrrr}
\hline & \multicolumn{3}{c}{ Status kemiskinan rumah tangga } \\
\cline { 2 - 5 } Variabel & \multicolumn{2}{c}{ Miskin } & Tidak miskin \\
\cline { 2 - 5 } & Rata-rata & Standar deviasi & Rata-rata & Standar deviasi \\
\cline { 2 - 5 } Modal sosial & 65,61 & 19,32 & 67,18 & 19,41 \\
Lama sekolah (tahun) & 4,72 & 4,17 & 7,39 & 4,84 \\
Jenis kelamin (1=laki-laki) & 0,86 & 0,34 & 0,86 & 0,35 \\
Umur (tahun) & 46,60 & 13,71 & 47,41 & 13,70 \\
Status perkawinan (1=kawin) & 0,81 & 0,39 & 0,82 & 0,38 \\
Ukuran rumah tangga & 3,91 & 1,74 & 3,80 & 1,71 \\
\hline
\end{tabular}

Tabel 2 menunjukkan statistik deskriptif masing-masing variabel yang digunakan dalam analisis menurut status kemiskinan rumah tangga. Kepala rumah tangga miskin memiliki rata-rata lama sekolah (pendidikan) yang lebih rendah dibanding kepala rumah tangga tidak miskin. Jumlah anggota rumah tangga yang lebih besar banyak dijumpai pada rumah tangga miskin. Rata-rata indeks modal sosial di rumah tangga tidak miskin sebesar 67,18 lebih tinggi dibanding rumah tangga miskin sebesar 65,61.

\section{Uji Endogenitas Modal Sosial}

Uji endogenitas penting dilakukan untuk menentukan metode yang tepat dalam melakukan analisis. Ketika variabel tak bebas bukan merupakan variabel endogen, maka metode probit biasa bisa 
digunakan, sebaliknya jika ternyata variabel tak bebas tersebut adalah variabel endogen maka metode 2PLS lebih tepat digunakan ketimbang menggunakan metode probit biasa. Adapun tes yang bisa digunakan untuk melihat apakah suatu variabel tersebut endogen atau bukan adalah dengan menggunakan prosedur uji Hausman. berikut ini adalah hasil dari uji endogenitas modal sosial

- Hipotesis

$H_{0}: \lambda=0$ (variabel modal sosial eksogen)

$H_{1}: \lambda \neq 0$ (variabel modal sosial endogen)

- Statistik uji

\begin{tabular}{cccc}
\hline$\hat{\lambda}$ & Standard error & $Z$ & $p$-value \\
\hline 0,0054 & 0,0016 & 3,375 & 0,001
\end{tabular}

- Kriteria pengujian, $H_{0}$ ditolak jika $p$-value $\leq \alpha=0,05$

- Kesimpulan.

Nilai $p$-value yang dihasilkan sebesar $0,001<0,05$ sehingga $H_{0}$ ditolak, maka disimpulkan bahwa variabel modal sosial adalah variabel endogen.

\section{Hasil Two Probit Least Square (2PLS)}

Dari uji endogenitas yang telah dilakukan, diperoleh informasi bahwa variabel modal sosial adalah variabel endogen, sehingga metode 2PLS lebih tepat digunakan ketimbang metode regresi probit biasa. Tabel 3 menyajikan hasil taksiran koefisien instrumen variabel dan variabel eksogen dalam model terhadap modal sosial (tahap pertama).

Tabel 3. Hasil Pendugaan Tahap Pertama 2PLS.

\begin{tabular}{|c|c|c|c|c|}
\hline \multirow{2}{*}{ Variabel } & \multicolumn{4}{|c|}{ Variabel tidak bebas: modal sosial } \\
\hline & Koef. & Standard error & $\mathbf{z}$ & $p$-value \\
\hline Lama sekolah & $-0,012$ & 0,014 & $-0,88$ & 0,038 \\
\hline Jenis Kelamin ( $1=$ laki-laki) & 1,981 & 0,312 & 6,35 & 0,000 \\
\hline Umur & 0,045 & 0,006 & 7,54 & 0,000 \\
\hline Status perkawinan ( $1=$ kawin) & 4,649 & 0,293 & 15,89 & 0,000 \\
\hline Ukuran rumah tangga & 0,378 & 0,043 & 8,82 & 0,000 \\
\hline Lama tinggal & 0,096 & 0,004 & 20,81 & 0,000 \\
\hline Banyak organisasi & 9,102 & 0,140 & 64,96 & 0,000 \\
\hline Konstanta & 51,672 & 0,378 & 136,47 & 0,000 \\
\hline
\end{tabular}

Dari tabel 3 terlihat bahwa kedua instrumen variabel yang digunakan yaitu lama tinggal dan banyaknya organisasi yang diikuti merupakan instrmen yang cukup baik, hal ini terlihat dari koefisien yang signifikan. Selanjutnya nilai residual yang diperoleh pada tahap pertama dimasukkan ke model probit sebagai variabel bebas, hasil taksiran parameter pada tahap kedua dapat dilihat pada tabel 4 .

Tabel 4. Hasil Pendugaan Tahap Kedua 2PLS.

\begin{tabular}{|c|c|c|c|c|}
\hline \multirow{2}{*}{ Variabel } & \multicolumn{4}{|c|}{ Variabel tidak bebas: miskin ( $1=$ miskin dan $0=$ tidak miskin) } \\
\hline & Koef. & Standard error & $\mathbf{z}$ & $p$ - value \\
\hline Modal sosial & $-0,0057$ & 0,0015 & $-3,74$ & 0,000 \\
\hline Lama sekolah & $-0,0574$ & 0,0015 & $-36,59$ & 0,000 \\
\hline Jenis Kelamin ( $1=$ laki-laki) & 0.0630 & 0,0326 & 1,93 & 0,026 \\
\hline Umur & $-0,0013$ & 0,0006 & $-2,37$ & 0,009 \\
\hline Status perkawinan (1=kawin) & $-0,0395$ & 0,0311 & $-1,27$ & 0,102 \\
\hline Ukuran rumah tangga & 0,0082 & 0,0045 & 1,84 & 0,033 \\
\hline Residual & 0,0054 & 0,0016 & 3,38 & 0,001 \\
\hline Konstanta & $-0,7333$ & 0,0947 & $-7,74$ & 0,000 \\
\hline
\end{tabular}


Dari tabel 4 di atas terlihat bahwa variabel-variabel yang signifikan berpengaruh terhadap peluang rumah tangga menjadi miskin adalah modal sosial, lama sekolah, umur dan ukuran rumah tangga.

\section{Efek Marginal}

Efek marginal dari faktor-faktor yang signifikan mempengaruhi peluang rumah tangga menjadi miskin disajikan pada tabel 5. Efek marginal dihitung dengan menggunakan perkiraan perbedaan peluang menjadi miskin ketika faktor-faktor yang memengaruhi tersebut mengalami perubahan (misalnya peluang rumah tangga menjadi miskin ketika lama sekolah kepala rumah tangga meningkat).

Tabel 5. Efek Marginal Faktor-Faktor Yang Memengaruhi Peluang Rumah Tangga Menjadi Miskin.

\begin{tabular}{lc}
\hline Variabel & Perubahan Peluang rumah tangga miskin \\
\hline Modal sosial & $-0,00073$ \\
Lama sekolah (tahun) & $-0,00735$ \\
Umur & $-0,00017$ \\
Ukuran rumah tangga & 0,00106 \\
\hline
\end{tabular}

Tabel 5 menunjukkan efek marginal faktor-faktor yang memengaruhi peluang rumah tangga menjadi miskin. Efek marginal modal sosial rumah tangga terhadap peluang rumah tangga menjadi miskin adalah -0,00073. Hal ini berarti peningkatan satu satuan modal sosial rumah tangga akan mengakibatkan peluang rumah tangga menjadi miskin berkurang sekitar 0,00073. Demikian pula, efek marginal penambahan satu tahun lama sekolah kepala rumah terhadap peluang menjadi miskin adalah $-0,00735$. Hal ini menyiratkan bahwa setiap terjadi peningkatan satu tahun lama sekolah kepala rumah tangga maka peluang rumah tangga menjadi miskin berkurang sekitar 0,00735. Efek marginal peningkatan umur kepala rumah tangga terhadap kemungkinan menjadi miskin adalah -0,00017. Temuan ini menunjukkan bahwa setiap peningkatan satu tahun umur kepala rumah tangga sampai pada batas usia produktif akan mengakibatkan peluang rumah tangga menjadi miskin berkurang sekitar 0,00017. Efek marginal peningkatan ukuran rumah tangga terhadap kemungkinan menjadi miskin adalah 0,0011 . Temuan ini menunjukkan bahwa setiap penambahan satu anggota rumah tangga akan mengakibatkan peluang rumah tangga menjadi miskin bertambah sekitar 0,0011.

\section{Kesimpulan}

Hasil analisis menunjukkan adanya endogenitas modal sosial di dalam model status kemiskinan rumah tangga di Indonesia. Untuk mengatasi masalah endogenitas, penelitian ini menggunakan metode 2PLS dengan menggunakan variabel instrumen modal sosial yaitu lama tinggal dan banyaknya organisasi yang diikuti. Kedua instrumen ini berkorelasi dengan modal sosial, tetapi tidak berkaitan langsung dengan kemiskinan.

Modal sosial berpengaruh negatif terhadap peluang rumah tangga menjadi miskin, dimana setiap peningkatan satu satuan modal sosial maka peluang rumah tangga menjadi miskin berkurang sebesar 0,0007346. Begitu juga dengan modal manusia (dalam hal ini lama sekolah dan umur) berpengaruh negatif terhadap peluang rumah tangga menjadi miskin, sedangkan ukuran rumah tangga berpengaruh positif terhadap peluang rumah tangga menjadi miskin.

\section{Referensi}

[1] Asian Development Bank. 2017. Kemiskinan di Indonesia. diakses tanggal: 3 Oktober 2018, tersedia pada https://www.adb.org/id/indonesia/poverty.

[2] Ikhsan, M. 1999. The Disaggregation of Indonesian Poverty: Policy and Analysis. Ph.D.Dissertation. University of Illinois, Urbana.

[3] Fukuyama F. 1995. Trust: The social virtues and the creation of prosperity, Free press New York.

[4] Coleman JS. 1988. Social capital in the creation of human capital. American journal of sociology: S95-S120.

[5] Putnam R. 1993. The prosperous community: social capital and public life. The american prospect 13(Spring), Vol. 4. 
[6] Woolcock M, Narayan D. 2000. Social capital: Implications for development theory, research, and policy. The Instruments. Econometrica, Vol. 65. 557-586.

[7] Healy K, Hampshire A. 2002. Social capital: a useful concept for social work. Australian Social Work 55(3): 227238.

[8] Adepoju A, Oni O. 2012. Investigating Endogeneity Effects of Social Capital on Household Welfare in Nigeria: A Control Function Approach. Quarterly Journal of International Agriculture 51(1): 73.

[9] BPS. 2013. Statistik Modal Sosial 2012. Jakarta, Indonesia: BPS-Statistics Indonesia.

[10] Hill R, Griffiths W. 2011. Principles Of Econometrics 4th. New York: Jhon Wiley \& Sons.

[11] Rivers D, Vuong Q. Limited Information Estimators And Exogeneity Staiger D, Stock J. 1997. Instrumental Variables Regression with Weak world bank research observer 15(2): 225-249. (1988). 